\title{
Dying to find the source - the use of rhodamine WT as a proxy for soluble point source pollutants in closed pipe surface drainage networks
}

\author{
C. H. Mines, A. Ghadouani, and G. N. Ivey
}

School of Environmental Systems Engineering, The University of Western Australia, 35 Stirling Highway (M015), Crawley, Western Australia, 6009, Australia

Received: 14 May 2009 - Published in Hydrol. Earth Syst. Sci. Discuss.: 23 June 2009

Revised: 30 October 2009 - Accepted: 30 October 2009 - Published: 12 November 2009

\begin{abstract}
Rhodamine WT (RWT), a xanthene dye, may serve as a proxy for soluble pollutants within quantitative tracing studies investigating point source contaminant transport. This study quantified the effects of altering the concentration, $\mathrm{pH}$, temperature and salinity of a RWT solution on the detected fluorescence of RWT within the laboratory prior to a field release of RWT within a closed pipe urban drainage network. All RWT solutions exhibited stability and $<10 \%$ variation from the expected concentration over a thirteen hour laboratory study period; $\mathrm{pH}$ related quenching of RWT fluorescence of up to $14.9 \%$ was observed for solutions with $\mathrm{pH}<3.9$; and increasing salinity of RWT solution was found to have a negligible quenching effect. In direct contrast to previous studies RWT fluorescence was found to directly correlate with temperature of solution, and a temperature correction factor was determined and tested. The field release study succeeded in detecting RWT at concentrations two orders of magnitude greater than background fluorescence. Based on longitudinal dispersion theory, observed RWT peak concentrations were within $10 \%$ of predicted peaks.
\end{abstract}

\section{Introduction}

Contamination of surface and groundwater from anthropogenic sources has become widespread in most developed areas of the world. The management of such contamination is complicated by difficulties in identifying point sources. Water tracers such as the xanthene dye Rhodamine WT (RWT) can be utilised in the investigation of contaminant transport in hydraulic systems to examine the transport of solutes (Broshears et al., 1996; Hibbs et al., 1998; Fox et al., 2002; Gaikowski et al., 2004; Richardson et al., 2004;

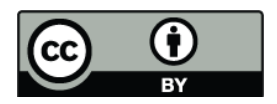

Correspondence to: A. Ghadouani (anas.ghadouani@uwa.edu.au)
Mukherjee et al., 2005), and thus trace contaminants back to their source (Pitt et al., 1993; Lalor and Pitt, 1999; Close et al., 2002; Pitt, 2002). Whilst information regarding time of travel and flow velocity may be determined through qualitative applications of tracers, quantitative tracing is required for more precise hydrological information such as potential contaminant transport characteristics. Quantitative tracing can therefore serve an invaluable purpose in contaminant fate and transport investigation.

In order to conduct meaningful quantitative tracer studies it is necessary to understand the processes that may contribute to loss of RWT in solution, and thus affect conservation of the tracer. Although RWT has been used as a surface and groundwater tracer since its formation in 1968, its use in quantitative tracer studies has been shown to be compromised by quenching of RWT fluorescence at $\mathrm{pH}$ values below 5 (Smart and Laidlaw, 1977; Tai and Rathbun, 1988; Kasnavia et al., 1999) and by dissolved salts (Smart and Laidlaw, 1977); fluorescence intensity of RWT varying inversely with temperature (Smart and Laidlaw, 1977; Wilson et al., 1986); and occasionally elevated background fluorescence in natural waters (Smart and Karunaratne, 2002). Previous work has also demonstrated that turbidity may significantly interfere with fluorescence measurements given the ability of suspended solids to contribute to background fluorescence (Smart and Laidlaw, 1977), and the use of fluorometers must be questioned in turbid environments. The potential for turbidity to impact upon our field study was assessed by measuring a range of RWT solutions prepared using water from our field site, and no significant deviation from expected fluorescence was observed hence any possible effects of turbulence on RWT fluorescence measurements were ignored for the remainder of the study. A number of studies have also demonstrated that the use of RWT in quantitative studies may be compromised by photochemical decay of RWT over time (Smart and Laidlaw, 1977; Tai and Rathbun, 1988; Suijlen and Buyse, 1994; Upstill-Godard et al., 2001; Dierburg and

Published by Copernicus Publications on behalf of the European Geosciences Union. 
DeBusk, 2005) and loss of RWT due to adsorption (Smart and Laidlaw, 1977; Wilson et al., 1986; Sabatini and Austin, 1991; Shiau et al., 1993; Di Fazio and Vurro, 1994; Soerens et al., 1994; Kasnavia et al., 1999; Close et al., 2002; Keefe et al., 2004; Kung et al., 2000; Vasudevan et al., 2001; Lin et al., 2003; Pang et al., 2003; Richardson et al., 2004; Dierburg and DeBusk, 2005) but as the work described here focused on the use of RWT within a closed pipe surface water drainage network these potential losses were deemed insignificant and not re-examined. Given this range of potential compromising factors, the inconsistent nature of field results concerning RWT fate and transport (Tai and Rathbun, 1988; Jones and Jung, 1990; Suijlen and Buyse, 1994; Ptak and Schmid, 1996; Kung et al., 2000; Upstill-Godard et al., 2001; Close et al., 2002; Lin et al., 2003) is unsurprising.

Further complicating the task of contaminant source tracing is the often episodic nature of contamination events, either due to intermittent delivery or intermittent mobilisation from contaminant pools. This highlights the need for high resolution temporal data which can best be obtained through the use of in situ instrumentation as opposed to the traditional bench top fluorometry. Although gaining in popularity, in situ fluorometric analysis remains a relatively new technology in comparison to bench top or pump-through fluorometric analysis methods.

The objective of this work was therefore to evaluate, despite its possible reactivity, the effective use of RWT as a proxy for soluble point source pollutants, with the goal of conducting in situ RWT detection studies in the field. The effects of altering the initial concentration, $\mathrm{pH}$, temperature and salinity of a RWT solution on the detected fluorescence of RWT were separately quantified within the laboratory. The purpose of this separate quantification was to aid in the understanding of the contribution of each of the water quality parameters on the RWT measurements collected in the field, particularly as it is likely that such water quality parameters can be highly variable within drainage and natural waters. It was anticipated that 1) the fluorometer would exhibit accuracy of $\pm 6 \%$ of the known RWT concentration within the calibration concentration range; 2) quenching of RWT fluorescence would be observed within solutions below $\mathrm{pH}$ of 5; 3) RWT fluorescence would vary inversely with temperature of solution and 4) quenching of RWT fluorescence would be observed within saline solutions.

A field release and detection of RWT within a closed pipe urban drainage network was then conducted with the aim of analysing the resultant peaks in measured RWT to relate peak characteristics with flow and release conditions. Through evaluation and field use of a in situ fluorometer specific to RWT, this work ultimately aimed to improve the quantitative application of RWT as a proxy for soluble contaminants in constructed drainage networks and natural waterways, and to explore a method by which to relate detected contaminant peaks with flow conditions and location of contaminant release.

\section{Materials and methods}

\subsection{In situ instrumentation}

Liquid RWT containing $20 \%$ true dye and $80 \%$ carrier was used to make a stock RWT solution at $100 \mathrm{mg} \mathrm{L}^{-1}$ that was used throughout this study. RWT was measured in the laboratory and field using the in situ YSI 6130 RWT fluorometer and YSI 6820 sonde, with data logged by the YSI 650 Multiparameter Display Logger. The 6130 RWT fluorometer light source has a peak wavelength of $540 \mathrm{~nm}$ whilst the optical filter transmits light from 570 to $590 \mathrm{~nm}$ to the photodetector. It may be calibrated using two or three points, and for the purposes of this study a 3 -point calibration was conducted using 0,100 and $200 \mu \mathrm{g} \mathrm{L}^{-1}$ true dye RWT solutions. Summing the accuracy of the fluorometer and potential calculation error associated with preparation of the solutions results in a total potential error of $\pm 6 \%$. Differences between measured and expected concentrations may therefore only be described as significant if greater than $\pm 6 \%$.

In addition to RWT the YSI 6820 sonde also measured dissolved oxygen concentration, temperature, specific conductance, salinity, oxidation reduction potential and $\mathrm{pH}$. The $4 \mathrm{C}$ cell battery configuration allowed for approximately $45 \mathrm{~h}$ of continuous (every second) data collection. Within the laboratory the sonde was held upright via a metal clamp stand and the RWT solutions were placed in the $200 \mathrm{~mL}$ calibration cup supplied with the sonde. In the field the sonde was suspended via a rope from an access ladder, remaining submerged during the data collection period.

\subsection{Field sampling sites}

Water was collected in July 2006 from the surface of the Swan River, Perth, Australia, at the Royal Perth Yacht Club jetty for use within the laboratory to determine the accuracy of the RWT fluorometer in natural surface water. The water collected was slightly brown in colour, contained some dark particulates, had a $\mathrm{pH}$ of 7.5 and detected salinity and specific conductance were below the detection limits of $0.01 \mathrm{ppt}$ and $0.001 \mathrm{~m} \mathrm{Scm}^{-1}$ respectively.

The field work component of this study was carried out at the drain inlet of Whaleback Lake, a compensating basin in Whaleback Golf Course, Parkwood, Australia, located within the Bannister Creek Catchment of the Canning River. Land use upstream of Whaleback Lake varies considerably from tile manufacture, fibre cement sheeting, food processing, heavy construction, machinery maintenance and general commercial development, with a number of land uses present which have the potential to contaminate the stormwater system (Morrison, personal communication, 19 September 2006). This proximity to potential contaminant sources, in conjunction with anecdotal evidence of businesses upstream illicitly discharging contaminants into the stormwater system, was the primary reason behind selection of the 
Whaleback Lake study site. Whaleback Lake has also been identified by the Bannister Creek Catchment Group as an important part of the Bannister Creek Catchment, providing a valuable habitat corridor between the Tom Bateman Wetland, Bannister Creek and the Canning River. Water quality in Whaleback Lake is highly variable as later discussed.

\subsection{Laboratory methodology}

A series of fifteen solutions made using both deionised water and Swan River water, ranging from 0 to $280 \mu \mathrm{g} \mathrm{L}^{-1}$ true dye RWT concentration, were measured to assess the accuracy of the fluorometer within and above the calibration range. Each solution was prepared through the addition of an appropriate amount of previously prepared $100 \mathrm{mg} \mathrm{L}^{-1}$ true dye RWT stock solution to deionised or Swan River water at room temperature. Upon introduction of the fluorometer to the solution, RWT concentration readings were taken over a period of $5 \mathrm{~min}$, at $30 \mathrm{~s}$ sampling intervals, to ensure short-term stability of the reading. This series of testing also examined longer term stability of the 10,60,140, 190 and $240 \mu \mathrm{g} \mathrm{L}^{-1} \mathrm{RWT}$ solutions over $13 \mathrm{~h}$ at room temperature and under mild fluorescent lighting.

Fluorometric analysis was also performed on $100 \mu \mathrm{g} \mathrm{L}^{-1}$ RWT solutions made with Swan River water, to which either hydrochloric acid or sodium hydroxide solutions had been added to alter the $\mathrm{pH}$, achieving a total $\mathrm{pH}$ range of 2.68 to 10.48. Given that this process also increased the total volume of the solution being measured it was also necessary to apply a volumetric correction to adjust for the decrease in concentration due to the increase in volume.

The 6130 RWT fluorometer was calibrated using solutions at $16^{\circ} \mathrm{C}$ due to conditions in the laboratory at the time of calibration. To quantify the effects of temperature on RWT fluorescence intensity 50, 100 and $150 \mu \mathrm{g} \mathrm{L}^{-1}$ true dye solutions were prepared using deionised water. Half of each concentration solution was chilled in a refrigerator whilst the other half was heated using a magnetic stirrer with heating element. Each solution was measured separately, with RWT concentration readings taken until the temperature of the solution either increased or decreased back to $16^{\circ} \mathrm{C}$.

Salinity quenching of RWT fluorescence was quantified through detection of RWT solutions to which sodium chloride had been added. Five tests were conducted using $100 \mu \mathrm{g} \mathrm{L}^{-1}$ true dye solution prepared with deionised water, with sodium chloride added to make concentrations of $0.005,0.05,0.1,0.5$ and $1.0 \mathrm{M} \mathrm{NaCl}$ respectively. Given that most seawater has a salinity of roughly $3.5 \%$ which equates to $0.6 \mathrm{M} \mathrm{NaCl}$ (if the total salinity were due to sodium chloride) this covers a range of salinities which may be encountered in field conditions. Data were collected over a period of approximately $60 \mathrm{~h}$.

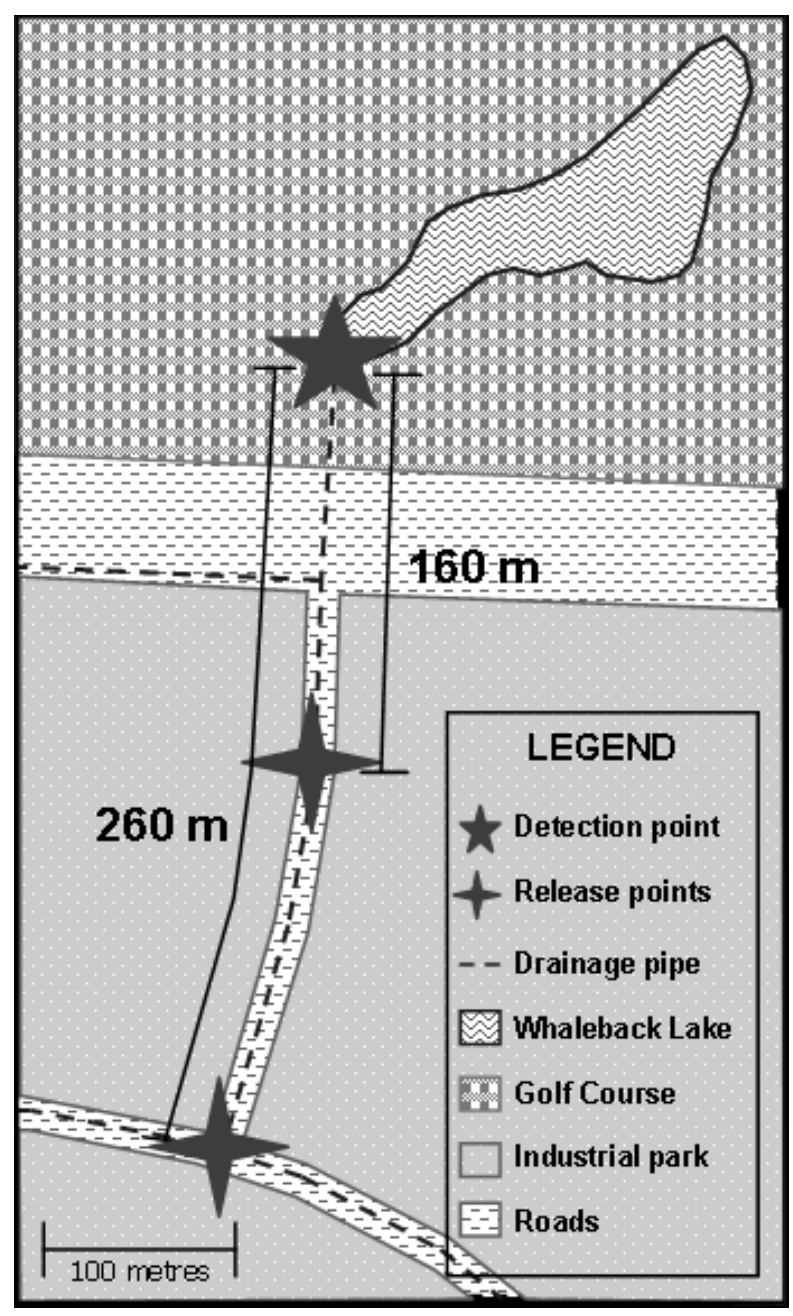

Fig. 1. Schematic of field release study site, showing the detection point located at the inlet of Whaleback Lake, located within the Whaleback Golf Course in Parkwood, Western Australia, and release points located upstream within an industrial area.

\subsection{Field methodology}

The sonde was moored at the inlet of Whaleback Lake on 25 August 2006 and set to take data every five minutes over a $65 \mathrm{~h}$ period. The purpose of this was to collect background fluorescence readings and to confirm the anecdotal evidence that water quality at the study site was both temporally variable and cause for concern.

A week after the background readings were taken the sonde was again moored at the lake inlet, and RWT was introduced into the piped drainage network upstream of the detection point (Fig. 1). Two RWT solutions were prepared by adding $25 \mathrm{~g}$ and $75 \mathrm{~g}$ of liquid RWT to two separate $5 \mathrm{~L}$ containers of deionised water, resulting in solutions containing $5 \mathrm{~g}$ and $15 \mathrm{~g}$ RWT true dye at approximately $1 \mathrm{~g} \mathrm{~L}^{-1}$ and $3 \mathrm{gL}^{-1}$ respectively. The $5 \mathrm{~g}$ RWT solution was released 
through a manhole $160 \mathrm{~m}$ upstream of the detection point, and upon the detected concentration returning to background levels the $15 \mathrm{~g}$ RWT was released through a manhole at a point $260 \mathrm{~m}$ upstream of the detection point. Although no quantitative flow measurements were taken, moderate flow rates were observed during the release period and no artificial mixing of the RWT within the pipe was undertaken. Data were collected continuously with the sonde during the entire release period.

\subsection{Data analysis}

All measured concentration values collected during the $\mathrm{pH}$ and temperature investigations were normalised around the known RWT concentration, such that the detected RWT concentrations in the natural $\mathrm{pH}$ and calibration temperature solutions were exactly equal to the known RWT concentration.

Two-parameter exponential decay regression lines were determined for each dataset in the temperature influence investigation, following a similar format to the relationship between sample temperature and RWT fluorescence presented by Smart and Laidlaw (1977). The resulting three equations relate the measured temperature (difference between calibration and measurement) with measured RWT concentration, thus describing the effect of temperature difference on accuracy of RWT concentration measurement. The exponential factors were averaged to determine an average relationship between temperature difference and measured RWT concentration, which in turn was rearranged to apply a correction factor to the concentration values collected during the temperature influence investigation.

Longitudinal dispersion analysis of the concentration peaks in RWT measured during the field release studies was undertaken with the objective of predicting the peaks given the flow conditions and mass released. Due to a lack of flow data, complete mass conservation of the first release was assumed, and trapezoidal integration under the observed time series conducted using MATLAB to determine the flow rate $Q$. This value of $Q$ was then applied to the second peak, and trapezoidal integration was conducted using MATLAB to determine the mass recovery of the second peak. The calculated flow rate $Q$ was also used to determine the crosssectional mean velocity $U$, using an estimation of $0.21 \mathrm{~m}^{2}$ for $A$, the cross-sectional area of the flow. This value for $A$ was calculated from the flow width $W$ of $2.1 \mathrm{~m}$ and flow depth $h$ of $0.1 \mathrm{~m}$ within the conduit immediately upstream of the sampling point. $U$ was in turn used to calculate the shear velocity $u^{*}$ using Eq. (1) (Fischer et al., 1979), estimating a Darcy-Weisbach friction factor $f$ of 0.02 (Fischer et al., 1979) given the flow velocity and material of the conduit.

$u^{*}=U \sqrt{\frac{f}{8}}$

Prior to applying longitudinal dispersion formulae, the "forgetting time" of the flow, after which the velocity of the flow is independent of the initial velocity (Fischer et al., 1979), was calculated using Eq. (2) (Fischer et al., 1979), using a flow depth $\mathrm{h}$ of $0.1 \mathrm{~m}$, to determine if constant coefficient longitudinal dispersion analyses were indeed applicable to the flow regime.

$T=4 \frac{h}{u^{*}}$

As the resulting $T$ was less than the time between release and detection, the longitudinal dispersion coefficient $\kappa_{x}$ in the stream-wise direction was calculated using Eq. (3) (Fischer et al., 1979) using a pipe width $W$ of $2.1 \mathrm{~m}$, and this $\kappa_{x}$ value was then used to predict the maximum peaks in RWT concentration for each of the two releases using Eq. (4) (Fischer et al., 1979).

$$
\begin{gathered}
\kappa_{x}=0.011 \frac{U^{2} W^{2}}{h u^{*}} \\
C_{\max }=\frac{M}{\sqrt{4 \pi \kappa_{x} t}}
\end{gathered}
$$

where $C_{\max }$ is the peak RWT concentration $\left[\mathrm{kg} \mathrm{m}^{-3}\right] ; M$ mass of dye per square metre of cross-sectional flow area $\left[\mathrm{kg} \mathrm{m}^{-2}\right]$ and $t$ is the time between release and detection of peak $[\mathrm{s}]$.

\section{Results and discussion}

\subsection{Background water quality data}

Results from the weekend data collection period at Whaleback Lake drain inlet (Fig. 2), conducted one week prior to the field release, demonstrate that background fluorescence is not an issue at this site, given the mean and maximum concentrations of $6.7 \mu \mathrm{g} \mathrm{L}^{-1}$ and $8.9 \mu \mathrm{g} \mathrm{L}^{-1}$ respectively. The results also provide evidence of water quality problems at the study site, primarily indicated by observed extremes in $\mathrm{pH}$. Values of $\mathrm{pH}$ greater than 9 can be toxic to aquatic organisms and have been associated with fish kills (Bergerhouse, 1994; Kann and Smith, 1999). There were four observed peaks in $\mathrm{pH}$ over the study period that exceeded this value, the largest value of 11.45 occurring at 05:07 on Saturday 26 August 2006. Whilst the cause of these peaks in $\mathrm{pH}$ is unknown, there is anecdotal evidence that a business or businesses within the catchment regularly clean their equipment late Friday night/early Saturday morning and it is likely that the peaks are a result of industrial cleaners entering the stormwater system.

\subsection{Stability of fluorescence}

All RWT solutions in DI and Swan River water exhibited fluorescence stability, and detected RWT concentrations were within $10 \%$ of the known RWT concentration over a $13 \mathrm{~h}$ period (Fig. 3). Fluorescence response between the DI and 


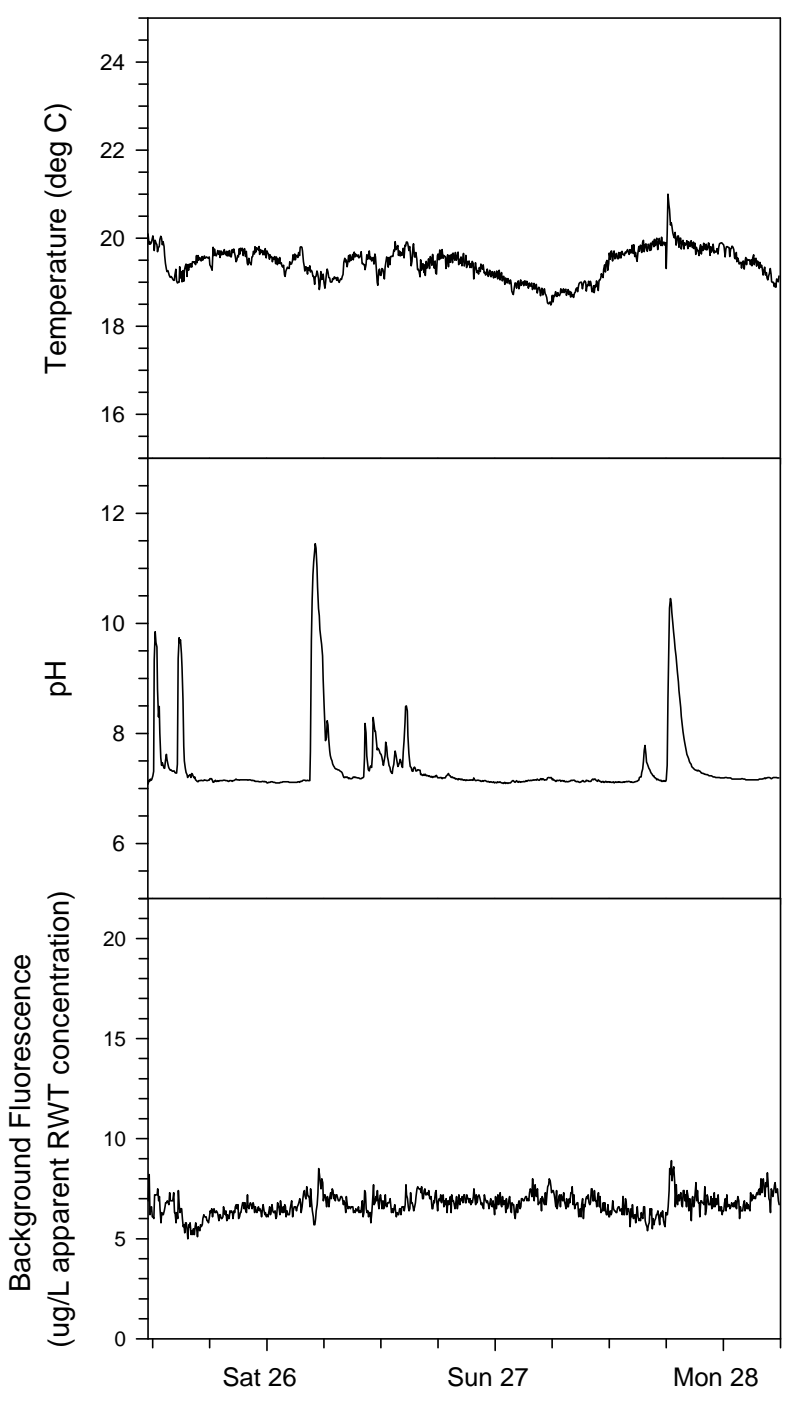

Fig. 2. Temperature, $\mathrm{pH}$ and background fluorescence in the RWT band of Whaleback Lake drain inlet water measured continuously over 11:30 25/08/06 to 06:00 28/08/06.

Swan River solutions was generally similar, suggesting little fluorescence interference due to natural environmental conditions of the Swan River water samples. Two of the eight solutions $-10 \mu \mathrm{g} \mathrm{L}^{-1}$ in Swan River water and $140 \mu \mathrm{g} \mathrm{L}^{-1}$ in deionised water - exhibited some percentage error values slightly greater than $\pm 6 \%$, although the mean percentage error values for all solutions fell within $\pm 6 \%$. The largest amount of variation from expected concentration and greater fluctuations in measured concentration exhibited by the $10 \mu \mathrm{gL}^{-1}$ solution may be explained by the lower signal: noise ratio for lower concentration solutions and possible interference due to natural background fluorescence. Given the stability of the readings and the lack of significant departure from $\pm 6 \%$ error for any of the eight tested solutions it was not anticipated that stability or accuracy of measurements would present problems in the field study.

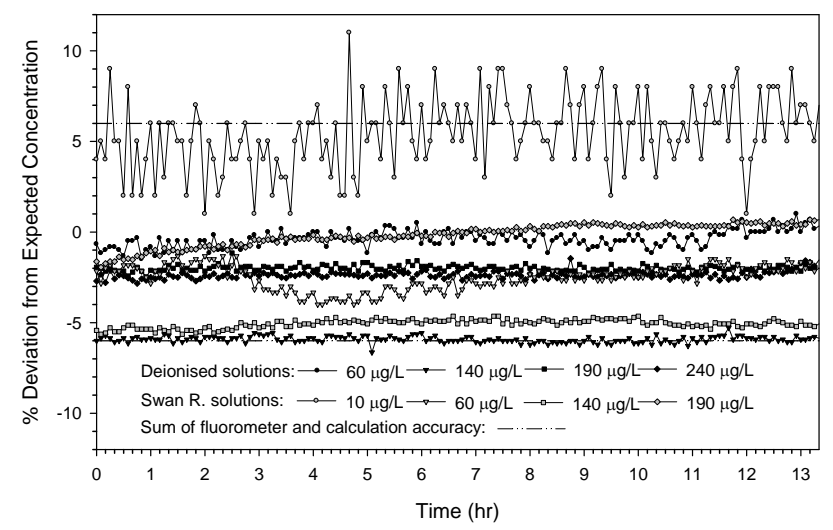

Fig. 3. Percentage deviation of measured RWT concentration from expected RWT concentration for solutions in deionised (black) and Swan River (grey) water, compared to sum of limit of accuracy of YSI 6130 fluorometer and calculation error.

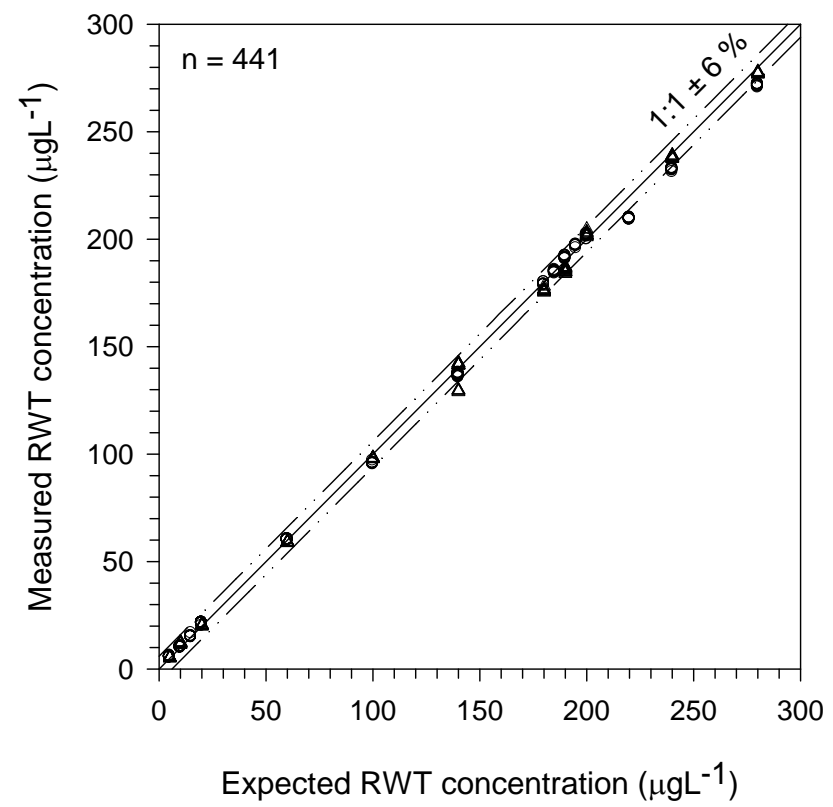

Fig. 4. Measured RWT concentration as a function of expected RWT concentration in deionised $(\bigcirc)$ and Swan River $(\triangle)$ water solutions; compared with the $1: 1$ line $(-)$ and $\pm 6 \%$ error (-..-). Concentration measurements were taken at $30 \mathrm{~s}$ intervals over a $5 \mathrm{~min}$ period for each solution. $R$ squared values relating each of the two datasets to the 1:1 line are 0.998 and 0.999 for the deionised and Swan River waters respectively.

\subsection{Concentration effects}

As demonstrated by the respective $R^{2}$ values of 0.998 and 0.999 for DI and Swan River waters (Fig. 4), the measured concentrations of RWT correlated extremely well with the expected concentrations of RWT in both sets of samples. The loss in accuracy of concentration measurement for expected 


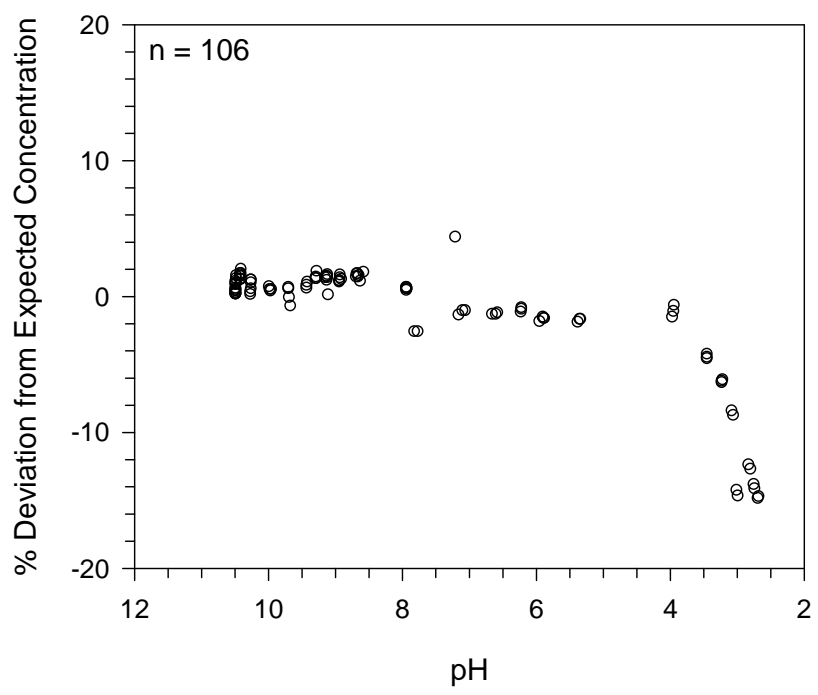

Fig. 5. Percentage deviation of measured RWT concentration from expected RWT concentration as a function of $\mathrm{pH}$ of the measured solution.

concentrations over $200 \mu \mathrm{g} \mathrm{L}^{-1}$, as shown by percentage errors in excess of $\pm 6 \%$, are unsurprising given that the three point calibration included 0,100 and $200 \mu \mathrm{g} \mathrm{L}^{-1}$ solutions. It may be possible to extend the range of the sensor by conducting the calibration using solutions of higher concentration, but this is not recommended as it contradicts the manufacturer instructions and may result in loss of resolution. It would be more appropriate to either dilute samples into the linear $0-200 \mu \mathrm{g} \mathrm{L}^{-1}$ range if necessary, or preferably to design experiments such that all measured solutions will fall within this range. The loss in accuracy at RWT concentrations higher than $200 \mu \mathrm{g} \mathrm{L}^{-1}$ did not affect the field work component of this study as all RWT concentration values measured in the field were below $200 \mu \mathrm{g} \mathrm{L}^{-1}$.

\section{4 pH effects}

Increasing the $\mathrm{pH}$ of the RWT solution above the ambient $\mathrm{pH}$, approximately 6.5 , was found to correspond to a slight $(<2 \%)$ increase in measured RWT, which is within the accuracy threshold of $\pm 6 \%$. More significant results were obtained when the $\mathrm{pH}$ was lowered, with clear evidence of $\mathrm{pH}$ related quenching of RWT fluorescence at $\mathrm{pH}$ values less than 3.9 (Fig. 5, note reverse order scaling of x-axis). Below this threshold value of $\mathrm{pH}$ the measured RWT concentration steadily decreases until the maximum underestimation of $14.9 \%$ RWT concentration is reached at $\mathrm{pH} 2.68$. These results exhibit a similar general trend to those presented by Smart and Laidlaw (1977) and Abood et al. (1969), though the threshold $\mathrm{pH}$ values presented in these previous studies are 5 and 4 respectively. A pKa of 5.1 has been observed for RWT (Shiau et al., 1993), meaning that in aqueous solution at $\mathrm{pH} 4.1$ (one log scale less than $\mathrm{pKa}$ ) the neutral form of

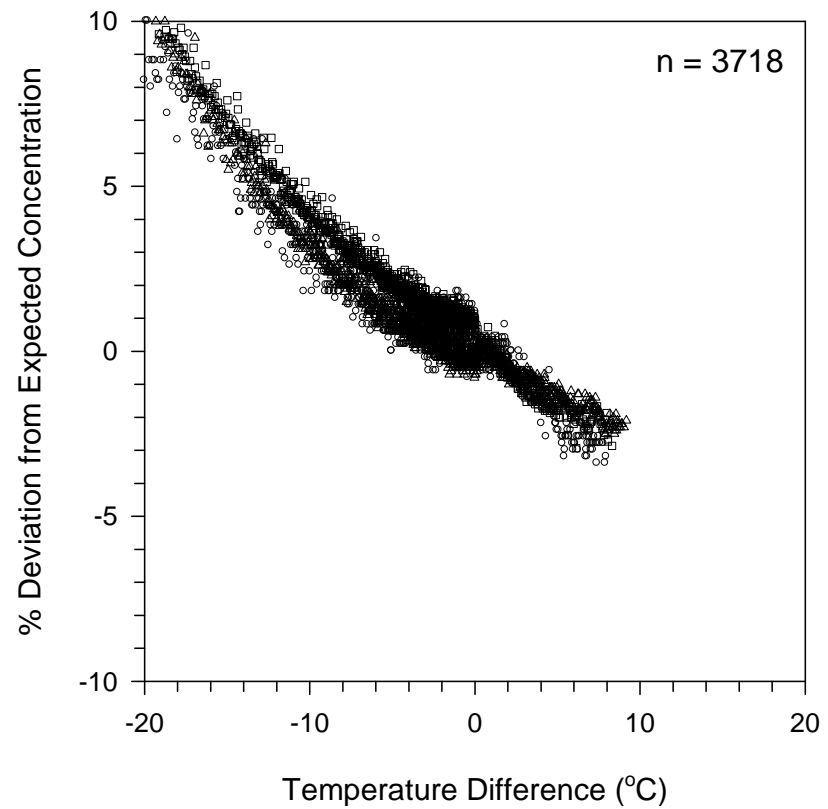

Fig. 6. Percentage deviation of measured RWT concentration from expected RWT concentration as a function of the difference in temperature between the measured solution and the calibration temperature of $16^{\circ} \mathrm{C}$ (calibration temperature - sample temperature). The three datasets shown correspond to expected solutions of $50 \mu \mathrm{g} \mathrm{L}$ ( $), 100 \mu \mathrm{g} \mathrm{L}(\triangle)$ and $150 \mu \mathrm{g} \mathrm{L}(\square)$.

RWT is dominant over the ionic form, thus it is anticipated that $\mathrm{pH}$ related quenching will occur in solutions less than or equal to $\mathrm{pH}$ 4.1.The observed $\mathrm{pH}$ threshold of 3.9 is in agreement with this expectation.

The implications for these results within the field work conducted in this study are negligible given that measured $\mathrm{pH}$ never fell below 7 over the weekend background sampling period or during the release of RWT. The underestimation of RWT due to low pH must, however, be accounted for during quantitative mass balance releases of RWT within low $\mathrm{pH}$ systems or those with variable water quality.

\subsection{Temperature effects}

Analysis for RWT at temperatures above the calibration temperature resulted in overestimations of RWT concentration, while conversely sampling at temperatures less than the calibration temperature resulted in underestimations of RWT concentration (Fig. 6, note Temperature Difference refers to calibration temperature minus sample temperature). These results contradict the conclusions of past studies that fluorescence intensity of RWT varies inversely with temperature (Smart and Laidlaw, 1977; Wilson et al., 1986). The YSI 6130 RWT fluorometer has an inbuilt temperature compensation function which may explain the departure from expected results, and if so it is apparent that overcompensation is occurring. Despite the maximum underestimation of RWT 
concentration of $3 \%$ falling within the $\pm 6 \%$ accuracy threshold and the maximum overestimation of $10 \%$ only exceeding the threshold by $4 \%$ there is a clear trend in the data. The discrepancy between the findings presented here and those previously presented may therefore have significant implications for quantitative RWT studies conducted in waters at temperatures different to the calibration temperature of the fluorometer used, particularly if the researcher assumes an inverse correlation between water temperature and RWT fluorescence.

Given the loss of accuracy due to sample temperatures differing from the calibration temperature a method of calculating a more accurate concentration value was determined. As previously discussed this was done by determining twoparameter exponential decay regression lines for each of the three datasets, resulting in the following relationships for the 50, 100 and $150 \mu \mathrm{g} \mathrm{L}^{-1}$ solution datasets respectively:

$$
\begin{aligned}
& C_{\text {measured }}=50 \exp (-0.0035 \Delta T)\left(R^{2}=0.88\right) \\
& C_{\text {measured }}=100 \exp (-0.0041 \Delta T)\left(R^{2}=0.92\right) \\
& C_{\text {measured }}=150 \exp (-0.00447 \Delta T)\left(R^{2}=0.96\right)
\end{aligned}
$$

where $C_{\text {measured }}$ is the measured RWT concentration for a given sample temperature, and $\Delta T$ is calculated by subtracting the sample temperature from the calibration temperature.

The exponential decay factors were then averaged to construct an equation relating the actual RWT concentration (50, 100 or $150 \mu \mathrm{g} \mathrm{L}^{-1}$ for each dataset respectively) with the difference in temperature:

$$
C_{\text {actual }}=\frac{C_{\text {measured }}}{\exp (-0.004 \Delta T)}
$$

Equation (8) was applied to the normalised concentration values shown in Fig. 6, the results of which are shown in Fig. 7. Use of the correction factor provided approximations within 3\% for the actual concentration of RWT present in solutions over a range of temperatures though was most accurate over the range $-10^{\circ} \mathrm{C}<\Delta T<10^{\circ} \mathrm{C}$. The correction factor was not applied to data collected during the field release due to the negligible difference between sample temperature and calibration temperature.

\subsection{Salinity effects}

An increase in concentration of sodium chloride in a $100 \mu \mathrm{g} \mathrm{L}^{-1}$ RWT solution corresponded with a slight decrease in measured concentration of RWT (Fig. 8). The maximum underestimation of RWT was $4.7 \%$, at $0.5 \mathrm{M}$ sodium chloride. Every concentration data point collected fell within the $\pm 6 \%$ accuracy threshold, thus the decrease in measured concentration may not be directly attributed to the salinity of the solutions.

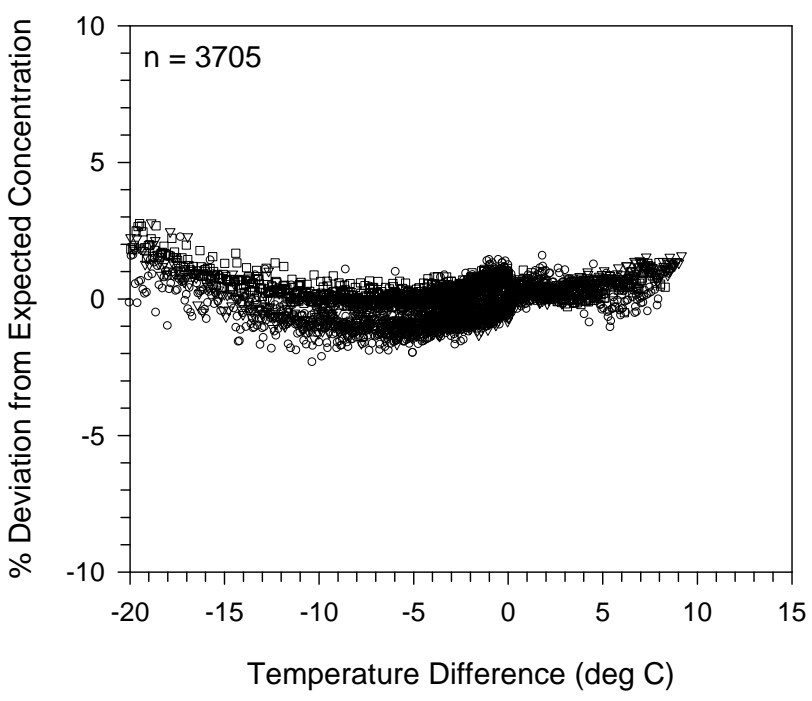

Fig. 7. Percentage deviation of corrected measured RWT concentration from expected RWT concentration as a function of the difference in temperature between the measured solution and the calibration temperature of $16^{\circ} \mathrm{C}$ (calibration temperature - sample temperature). The three datasets shown correspond to expected solutions of $50 \mu \mathrm{g} \mathrm{L}(\bigcirc), 100 \mu \mathrm{g} \mathrm{L}(\nabla)$ and $150 \mu \mathrm{g} \mathrm{L}(\square)$.

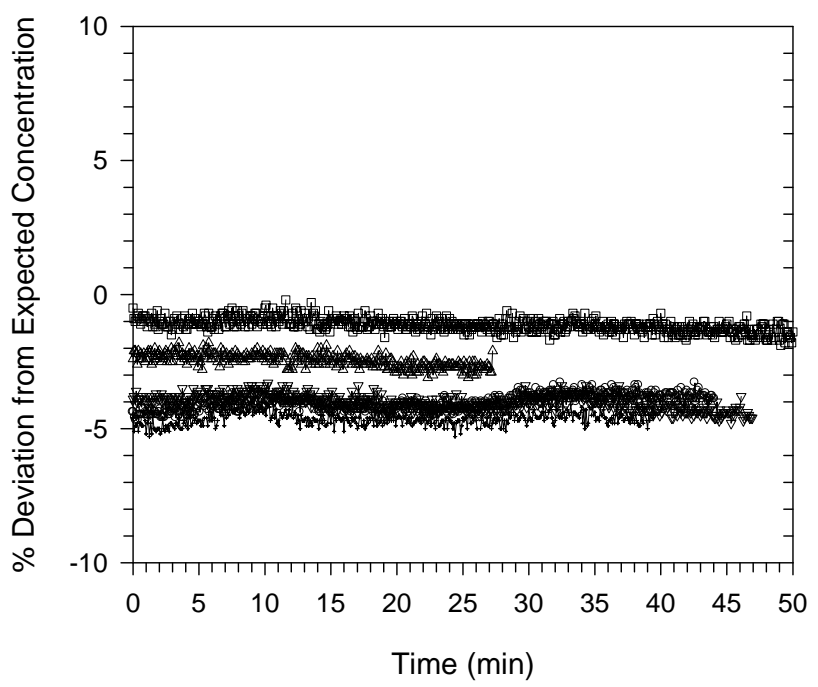

Fig. 8. Percentage deviation of measured RWT concentration from expected RWT concentration over time for a range of salinity concentrations $-1.0 \mathrm{M} \mathrm{NaCl}(\bigcirc), 0.5 \mathrm{M} \mathrm{NaCl}(\mid), 0.1 \mathrm{M} \mathrm{NaCl}(\triangle)$, $0.05 \mathrm{M} \mathrm{NaCl}(\square)$ and $0.005 \mathrm{M} \mathrm{NaCl}(\nabla)$.

These results are in agreement with an early series of tests conducted by Smart and Laidlaw (1977), where they measured a maximum loss in fluorescence of RWT of $8 \%$ at $0.5 \mathrm{M} \mathrm{NaCl}$. They are however substantially different to a more recent set of similar tests conducted by Smart and Laidlaw (1977), where they observed almost complete loss of RWT fluorescence at $0.5 \mathrm{M} \mathrm{NaCl}$ after equilibrium conditions were reached $(>93 \mathrm{~h})$. As the Whaleback Lake drain 
inlet water had a mean salinity measurement of $0.72 \mathrm{ppt}$ (equivalent to $0.012 \mathrm{M} \mathrm{NaCl}$ ), underestimation of RWT due to salinity was deemed to be of negligible effect to the field work results of this study. However if precise quantitative mass balance studies of RWT are performed, particularly within marine environments where the equivalent $\mathrm{NaCl}$ concentration is approximately $0.6 \mathrm{M}$, this underestimation is potentially problematic and may require adjustment of the data.

The laboratory component of this study demonstrates that local water quality conditions, particularly $\mathrm{pH}$ and temperature, must be measured and considered when conducting any quantitative RWT release study. This is of particular relevance when mass recovery is undertaken. There are also implications for the design stage of quantitative RWT release studies, for instance it may be necessary to perform calibration of the RWT fluorometer using solutions at a higher than standard temperature if the release is to be conducted in high temperature waters; or it may be necessary to release a larger mass of RWT if the study waters are acidic, low temperature or saline, to result in a significant peak in detected RWT concentration.

\subsection{Field release}

The field releases were easily detected (Fig. 9). At 09:48, four minutes after the $5 \mathrm{~g}$ release of RWT there was a peak in measured RWT concentration of $46.1 \mu \mathrm{g} \mathrm{L}^{-1}$. At 10:11, seven minutes after the $15 \mathrm{~g}$ release of RWT there was a peak in measured RWT concentration of $107.1 \mu \mathrm{g} \mathrm{L}^{-1}$ followed at 10:15 by another peak of $110.6 \mu \mathrm{g} \mathrm{L}^{-1}$. Both releases exhibited somewhat irregular decay curves, whilst the $15 \mathrm{~g}$ release decay curve displays a clear double peak. These characteristics may be due to the physical characteristics of the drainage system, such as the presence of input pipes between the release and detection points, and irregularities in flow regime. It is possible that the double peak is due to the presence of two RWT isomers commonly found in commercially available RWT, that have been shown to adsorb to different extents (Vasudevan et al., 2001) and thus exhibit contrasting times of travel, although this possibility was not explored further in this work.

The first release of RWT resulted in a peak approximately eightfold greater than background levels, whilst the second release peaked at two orders of magnitude greater than background levels whilst remaining within the range of the RWT sensor. Given the lack of variability in the ambient detected fluorescence it may therefore be concluded that both peaks resulted from their respective RWT releases and were not due to background fluorescence. This distinction is essential in order to prove the connection between two points of the drainage system, for instance cases where contaminant point sources are suspected but unproven.

Integration of the first detected peak in RWT concentration produced a flow rate $Q$ of $0.39 \mathrm{~m}^{3} \mathrm{~s}^{-1}$. Applying this flow

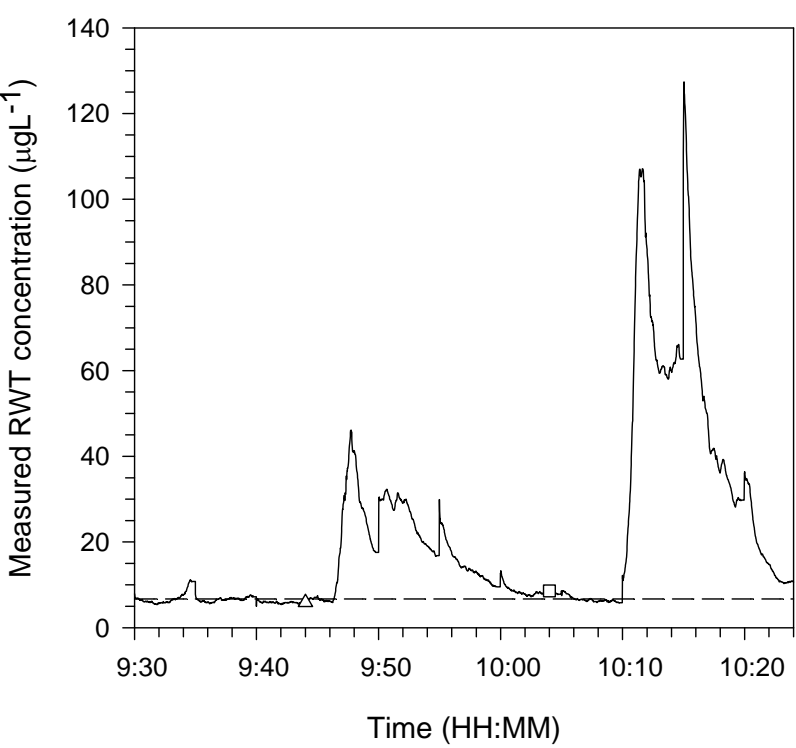

Fig. 9. Continuously measured RWT concentration at Whaleback Lake drain inlet over the field released period on 8 September 2006. $5 \mathrm{~g}$ RWT was released $160 \mathrm{~m}$ upstream from the drain inlet at 09:44 $(\triangle)$ and $15 \mathrm{~g}$ RWT was released $260 \mathrm{~m}$ upstream from the drain inlet at 10:04 ( $\square)$. The dashed line indicates the mean background fluorescence value equivalent to a RWT concentration of $6.7 \mu \mathrm{g} \mathrm{L}$ as detected over the weekend of 25 August 2006.

rate to the second detected peak in RWT concentration produced a mass recovery of $13.1 \mathrm{~g}(87 \%)$ for the second release. Complete mass conservation of the second release was not expected due to the inadvertent cessation of measurements prior to detection of the entire tail (Fig. 9) so this mass recovery confirmed that the flow rate was similar for both release periods. The cross-sectional mean velocity corresponding to the flow rate was $1.8 \mathrm{~ms}^{-1}$ whilst the shear velocity was $0.09 \mathrm{~ms}^{-1}$ using Eq. (1). In turn these values were applied to Eq. (2) to calculate a forgetting time of $4 \mathrm{~s}$ which is significantly less than the $180 \mathrm{~s}$ and $330 \mathrm{~s}$ times of travel between release and initial detection of RWT for each of the two respective releases, thus we may assume the flow velocity of the RWT laden water is independent of the initial release velocity and we may apply constant coefficient longitudinal dispersion analyses. The longitudinal dispersion coefficient $\kappa_{x}$ for the flow was calculated as $76 \mathrm{~m}^{2} \mathrm{~s}^{-1}$ using Eq. (4). The resulting prediction of the first peak in RWT concentration was calculated using Eq. (5) as $50 \mu \mathrm{g} \mathrm{L}^{-1}, 108 \%$ of the observed value of $46.1 \mu \mathrm{g} \mathrm{L}^{-1}$. Similarly the prediction of the second peak in RWT was $113 \mu \mathrm{g} \mathrm{L}^{-1}, 105 \%$ of the observed value of $107.1 \mu \mathrm{g} \mathrm{L}^{-1}$.

The success of this method in predicting the peaks in RWT concentration for each of the two releases demonstrates that longitudinal dispersion theory was indeed applicable in this flow regime and as such is likely to be applicable to predict peaks in similar flow scenarios. This method may then be 
extended to predict time of travel or distance from source given detected peak characteristics in order to identify the location of contaminant sources, and could be of particular value in cases where the source location is suspected but unproven. The method however does rely on the assumption of complete mass recovery of the first peak in RWT concentration, and estimations for flow depth and cross-sectional mean velocity as these parameters were not measured in the field. To conduct similar analysis in future studies it is recommended that flow velocity and depth/rate be measured concurrently during the RWT detection period.

\section{Conclusions}

The rapid changes in water quality at the study site, coupled with the potentially significant effects of local water quality conditions on detected RWT concentration highlight the value of in situ fluorometric methods to quantitative tracer release studies; the researcher can assess the measured concentration against real time water quality conditions. This assessment may then extend to post processing, or possibly real time correction of detected concentration values to account for any apparent over/underestimation of RWT in solution. Although RWT may be considered a conservative tracer and new in situ technologies allow for ease of detection in the field, it is still important to consider the processes concerning fluorescence and detection of the tracer. It is thus recommended that new users of this in situ fluorometric analysis technique, particularly within waters likely to express variability in water quality, quantify potential inaccuracies in RWT concentration measurements using similar methodology to that presented in this study. It may also be prudent to extend this methodology to examine the potential for interactions between multiple environmental factors and fluorometric response. The importance of this laboratory work prior to field deployment of the instrumentation is best highlighted in the direct contrast to previous studies of the results of the temperature laboratory study presented here. It is thus potentially necessary to examine even theoretically and empirically established relationships when engaging in the use of new technologies.

Acknowledgements. This work was supported by Pollution Response within the Department of Environment and Conservation of the Government of Western Australia. Support and assistance were also provided by the City of Canning, the South East Regional Centre for Urban Landcare (SERCUL) and The University of Western Australia. The authors are grateful to Dianne Krikke for assistance in the laboratory, to Jimmy Seow, Tim Mander, Peter Morrison, Alan Mihala, Don Fleming, Sefton Fearn, Ana Terrazas and Julie Roberts for assistance in the field work and to Norman Yan for providing comments on an earlier version of this manuscript.

Edited by: A. D. Reeves

\section{References}

Abood, K. A., Lawler, J. P., and Disco, M. D.: Utility of radioisotope methodology in estuary pollution control study, Report NY0-3961-1, US At. Energy Comm., New York, 1969.

Bergerhouse, D. L.: Lethal effects of elevated $\mathrm{pH}$ and ammonia on early life stages of hybrid striped bass, J. Appl. Aquaculture., 2, 81-100, 1994.

Broshears, R. E., Runkel, R. E., Kimball, B. A., McKnight, D. M., and Bencala, K. E.: Reactive solute transport in an acidic stream: Experimental $\mathrm{pH}$ increase and simulation of controls on $\mathrm{pH}$, aluminum and iron, Environ. Sci. Technol., 30, 3016-3024, 1996.

Close, M. E., Stanton, G. J., and Pang, L.: Use of rhodamine WT with XAD-7 resin for determining groundwater flow path, Hydrogeol. J., 10, 368-376, 2002.

Dierburg, F. E. and DeBusk, T. A.: An evaluation of two tracers in surface-flow wetlands: Rhodamine-WT and Lithium, Wetlands, 25, 8-25, 2005.

Di Fazio, A. and Vurro, M: Experimental tests using rhodamine WT as tracer, Adv. Water Resour., 17, 375-378, 1994.

Fischer, H. B., List, E. J., Koh, R. C. Y., Imberger, J., and Brooks, N. H.: Mixing in Inland and Coastal Waters, Academic Press, San Diego, CA, 1979.

Fox, A. M., Haller, W. T., Getsinger, K. D., and Petty, D. G.: Dissipation of triclopyr herbicide applied in Lake Minnetonka, MN concurrently with Rhodamine WT dye, Pest Manag. Sci., 58, 677-686, 2002.

Gaikowski, M. P., Larson, W. J., Steuer, J. J., and Gingerich, W. H.: Validation of two dilution models to predict chloramines-T concentrations in aquaculture facility effluent, Aquacult. Eng., 30, 127-140, 2004.

Hibbs, D. E., Parkhill, K. L., and Gulliver, J. S.: Sulfur hexafluoride gas tracer studies in streams, J. Environ. Eng.-ASCE., 124, 752760, 1998.

Kann, J. and Smith, V. H.: Estimating the probability of exceeding elevated $\mathrm{pH}$ values critical to fish populations in a hypereutrophic lake, Can. J. Fish. Aquat. Sci., 56, 2262-2270, 1999.

Kasnavia, T., Vu, D., and Sabatini, D. A.: Fluorescent dye and media properties affecting sorption and tracer selection, Ground Water, 37, 376-381, 1999.

Keefe, S. H., Barber, L. B., Runkel, R. L., Ryan, J. N., McKnight, D. M., and Wass, R. D.: Conservative and reactive solute transport in constructed wetlands, Water Resour. Res., 40, W01201, doi:10.1029/2003WR002130, 2004.

Kung, K.-J. S., Steenhuis, T. S., Kladivko, E. J., Gish, T. J., Bubenzer, G., and Helling, C. S.: Impact of preferential flow on the transport of adsorbing and non-adsorbing tracers, Soil Sci. Soc. Am. J., 64, 1290-1296, 2000.

Jones, D. R. and Jung, R. F.: Analytical problems arising from the use of bromide and rhodamine WT as co-tracers in streams, Wat. Res., 24, 125-128, 1990.

Lalor, M. and Pitt, R.: Use of tracers to identify sources of contamination in dry weather flow, Watershed Protection Techniques, 3 , 585-592, 1999.

Lin, A. Y.-C., Debroux, J-F., Cunningham, J. A., and Reinhard, M.: Comparison of rhodamine WT and bromide in the determination of hydraulic characteristics of constructed wetlands, Ecol. Eng., 20, 75-88, 2003. 
Mukherjee, A., Fryar, A. E., and Lasage, D. M.: Using tracer tests to assess natural attenuation of contaminants along a channelized coastal plain stream, Environ. Eng. Geosci., XI, 371-382, 2005.

Pang, L. P., Goltz, M., and Close, M.: Application of the method of temporal moments to interpret solute transport with sorption and degradation, J. Contam. Hydrol., 60, 123-134, 2003.

Pitt, R.: Emerging stormwater controls for critical sources areas. in: Management of Wet-Weather Flow in the Watershed, edited by: Field, R. and Sullivan, D., CRC Press, Boca Raton, FL, 1, 103-140, 2002.

Pitt, R., Lalor, M., Field, R., Adrian, D. D., and Barbe, D.: Investigation of Inappropriate Pollutant Entries into Storm Drainage Systems - A User's Guide, EPA/600/R-92/238, U.S. Environmental Protection Agency, Cincinnati, OH, 1993.

Ptak, T. and Schmid, G.: Dual-tracer transport experiments in a physically and chemically heterogeneous porous aquifer: effective transport parameters and spatial variability, J. Hydrol., 183, 117-138, 1996.

Richardson, S. D., Willson, C. S., and Rusch, K. A.: Use of rhodamine water tracer in the marshland upwelling system, Ground Water, 42, 678-688, 2004.

Sabatini, D. A. and Austin, T. A.: Characteristics of rhodamine WT and fluorescein as adsorbing ground-water tracers, Ground Water, 29, 341-349, 1991.

Shiau, B. J., Sabatini, D. A., and Harwell, J. H.: Influence of rhodamine WT properties on sorption and transport in subsurface media, Ground Water, 31, 913-920, 1993.
Smart, C. C. and Karunaratne, K. C.: Characterisation of fluorescence background in dye tracing, Environ. Geol., 42, p. 492, 2002.

Smart, P. L. and Laidlaw, I. M. S.: An evaluation of some fluorescent dyes for water tracing, Water Resour. Res., 13, 15-33, 1977.

Soerens, T. S. and Sabatini, D. A.: Cosolvency effects on sorption of a semipolar, ionogenic compound (rhodamine WT) with subsurface materials, Environ. Sci. Technol., 28, 1010-1014, 1994.

Suijlen, J. M. and Buyse, J. J.: Potentials of photolytic rhodamine WT as a large-scale water tracer assessed in a long-term experiment in the Loosdrecht Lakes, Limnol. Oceanogr., 39, 14111423, 1994.

Tai, D. Y. and Rathbun, R. E.: Photolysis of rhodamine-WT dye, Chemosphere, 17, 559-573, 1988.

Upstill-Godard, R. C., Suijlen, J. M., Malin, G., and Nightingale, P. D.: The use of photolytic rhodamines WT and sulpho G as conservative tracers of dispersion in surface waters, Limnol. Oceanogr., 46, 927-934, 2001.

Vasudevan, D., Fimmen, R. L., and Francisco, A. B.: Tracer-grade rhodamine WT: structure of constituent isomers and their sorption behaviour, Environ. Sci. Technol., 35, 4089-4096, 2001.

Wilson, J. F., Cobb, E. D., and Kilpatrick, F. A.: Applications of Hydraulics, Techniques of Water-Resources Investigations of the United States Geological Survey Book Three, USGS, Washington, DC, 1, 1-32, 1986. 